Vol. 8, N. 2, Year 2016

ISSN: 2037-0830 - DOI: 10.1515/rem-2016-0016

\title{
University knowledge exchange and the SKIN Project
}

\author{
Djelveh Sara ${ }^{\mathrm{a}}$, Contò Francesco ${ }^{\mathrm{b}}$ \\ ${ }^{a}$ University of Foggia, Department of Humanities, Italy, sara.djelveh@unifg.it \\ ${ }^{b}$ University of Foggia, Department of Economics, Italy, francesco.conto@unifg.it
}

\begin{abstract}
In this article, we present a rationale for investigating the role and contributions of universities to growth and sustainable development within the framework of the Europe 2020 Strategy (EU2020). To this extent, the literature suggests that the contemporary universities' mission in the knowledge society relies on their capacity to promote knowledge exchange. This allows expansion of the degree of intervention of universities in society and broadening of the institutional and policy frameworks within which they operate, opening to a wider range of possible contributions of social science and humanities to the EU2020 objectives, which are not limited to education and research policies.

We present the Short supply chain Knowledge and Innovation Network (SKIN) project (H2020-2016) ${ }^{l}$ as an example of a systemic approach to university-business-society dialogue, based on the role of universities as "knowledge hubs", (Yusuf, 2008) and aimed at promoting knowledge exchange and multi-actor cooperation. One of the main challenges of the project relies on the capacities of the involved actors to cooperate and, thus, on the mechanisms activated in order to ensure such collaboration. To this extent, the role of humanities and social sciences, in particular multidisciplinary and participatory research, is crucial for the success of the process of knowledge circulation within and for society.
\end{abstract}

Keywords: knowledge exchange, knowledge triangle, SKIN project, knowledge society, Europe 2020 Strategy

\section{Introduction}

In March 2010, the European Council launched the Europe 2020 Strategy (EU2020), as a comprehensive 10-year strategy for building a new European economy based on productivity, high rates of employment and social cohesion, i.e., a "smart, sustainable and inclusive" Europe.

Within this framework, Higher Education Institutions (HEIs) are identified as crucial partners in delivering the European Union's (EU's) strategy to drive and maintain sustainable, inclusive and smart growth. In particular, HEIs and their links with research-and-innovation actors and networks, specifically through the provision of the highly skilled human capital that Europe needs to boost entrepreneurship and create jobs, economic growth and prosperity, are considered at the core of both individual and societal development in Europe. ${ }^{2}$ Universities are thereby identified as the main sources of "knowledge and skilled employees" necessary for the sustainable development and economic growth of the EU (Kitson et al., 2009).

The acknowledged importance of HEIs within EU2020 reflects the recognition of such knowledge institutions for growth and development in the so-called knowledge society. The idea of knowledge society arises from the recognition of knowledge as an essential resource for the growth and development of economic systems. Phenomena such as globalisation, demographic change and the rapid diffusion of information and communications technologies (ICT) have radically changed the production systems, thus generating a new model in which human capital is at the core of economic development.

In such a framework, the role of HEIs itself adapts to the new and multifaceted global challenges that it is expected to address. The role of universities thereby addresses the increasing importance of knowledge as a pillar for achieving

${ }^{1}$ The research leading to these results has received funding from the Horizon Programme (Societal Challenge 2) under Research Executive Agency (REA) grant agreement number 728055. Reflects only the author's view, and the European Union is not liable for any use that may be made of the information contained therein.

${ }^{2}$ As outlined, among others, at the end of the INNOVEIT Conference held in May 2016 in Budapest by representatives of the European Institute of Innovation and Technology (EIT): "Social innovation and education (are) at heart of plans to boost European entrepreneurship" (EIT press release, Budapest, 2 May 2016). 


\section{University knowledge exchange and the SKIN Project \\ Djelveh, Contò}

interlinked social and economic objectives and reflects the acknowledgement of the role played by HEIs for social development and economic growth. To this extent, it can be argued that contemporary HEIs' mission relies on the ability of creating and properly disseminating "useful knowledge for the wider benefit of society" (Benneworth, 2011) or, in other words, on their capacity for promoting knowledge exchange.

\section{Universities and knowledge exchange}

The concept of knowledge exchange has been studied particularly intensely in the past years as a cross-cutting topic encompassing different disciplines and fields of activities (Mitton et al., 2007; Abreu et al., 2008; Yusuf, 2008; Cruickshank et al., 2012). Knowledge exchange can be defined as the iterative cycle of sharing ideas, research results, expertise or skills between interested parties, which enables the creation, transfer, adoption and exploitation of new knowledge in order to develop new products, processes or services and influence public policy (Lockett et al., 2008).

Even with the limits of such definition, this area tends to be very broad (Cruickshank et al., 2012). Benneworth (2011) argues that it is a valid lens for understanding the evolving role of HEIs within the framework of the knowledge society because it does not depict a brand new role for the universities, but it rather insists on activities in which universities have been always involved, thus allowing focussing on the social aspects related to the achievement of such activities. As Benneworth (2011) points out, this goes well beyond the academia-industry linkages and is not uniquely focussed on commercial activities. To this extent, the knowledge exchange approach is strongly connected with the idea of universities' third mission and, at the same time, would allow overcoming - or probably complementing - of the third mission vision (Benneworth, 2011). Knowledge exchange would thereby represent a systemic approach for evaluating the different activities of universities in the knowledge society, thus looking at the different "missions" of HEIs (education, research and engagement with society) in a unique framework, which implies strong linkages between universities and societies.

The idea of universities' third mission emerged in the $1980 \mathrm{~s}$ as a response to the crisis of the linear model of innovation. Innovation can be defined as the successful exploitation of new ideas into new products, processes, markets and ways of organising (Pittaway et al., 2004) and, thus, as the driving force behind economic development (Cantner et al., 2011). While innovation was traditionally regarded as a top-down process, starting from scientific knowledge towards innovators, it is now acknowledged as an interactive process that is determined not only by internal factors but also by external ones (Lasagni, 2012) and that requires cooperation between different actors, among which are research actors (Edquist, 2006; Tödtling and Trippl, 2005). This is particularly true in the knowledge society, where globalisation and the diffusion of ICTs have increased the global competition, thus making cooperation between different actors a critical success factor for the production of innovation (Kline and Rosenberg, 1986). The interactive model of innovation let emerge the idea that universities are not just involved in a top-down process in which they generate inputs that can be lately used by firms and other organisations for the production of innovation, but they are rather involved in an interactive and circular process of knowledge creation and circulation. In such process, universities are not the only actor bringing and circulating knowledge, thus moving the focus from the idea of knowledge transfer (the transfer of knowledge from universities to other actors) towards knowledge exchange, thus referring to the circulation of knowledge among different actors, including universities.

Based on such assumptions, the debate started looking at an additional mission for HEIs that is strongly linked with their engagement with the industry and, possibly, with the society at large (Vorley and Nelles, 2008). Such "new" mission is added to the traditional teaching and research activities, thus broadening the scope of universities' role within and for society and focussing on the social and economic impact of universities' activities.

The third mission's concept, similar to the knowledge exchange one, has been criticised because of its vague and general definition. As a result, on the one hand, the third mission has been often addressed as a residual term encompassing all university activities not covered by the first two missions (European Commission, 2008); on the other hand, it is not always possible to clearly distinguish among the different universities' activities and missions, because these can easily overlap (Jongbloed et al., 2008). In addition, the idea of the third mission seems in some way intended to change the nature of universities and not to address the real contemporary need for universities of producing knowledge through a set of overlapping and interactive processes (Benneworth, 2011) involving both external and internal stakeholders for the achievement of common and shared goals of growth and development.

The literature and the political debate have been particularly focussed on the process of knowledge exchange between actors that do not traditionally collaborate, looking at universities as both sources and channels of transmission of knowledge for the attainment of innovative services and products. To this extent, knowledge exchange can be interpreted as the process through which universities interact with the society at large, thus including and at the same time going beyond the traditional teacher-student relationship, involving external stakeholders (businesses, public authorities, other universities and institutions, non-governmental organisations [NGOs], etc.) in the co-creation of knowledge for delivering economic and societal benefits (Benneworth, 2011). In this sense, one of the main advantages of the knowledge exchange approach is the acknowledgement of the fact that knowledge processes are basically social processes (Paavola et al., 2004), thereby building on the interaction and cooperation among different actors. 


\section{University knowledge exchange and the SKIN Project \\ Djelveh, Contò}

Moreover, looking at universities' knowledge exchange activities does not imply changing the role of universities; rather, it provides a new lens of interpretation of the core activities and role of universities in modern society. Within this approach, the external relationships activated and maintained by HEIs play a crucial role in addressing the societal objectives that such actors are claimed to aim for. This opens a wide range of questions, including the need for investigating and understanding new ways of interaction among different actors, who often express different interests and speak different "languages", and thus for finding new forms of cooperation among them.

\section{The European policy framework for knowledge exchange}

The role and contributions of HEIs to knowledge exchange and to the development and growth of the EU constitute one of the main topics of the already mentioned EU2020 Strategy.

EU2020 was launched in March 2010 as a comprehensive strategy for getting the EU out of crisis and for building the European economy for the next decade. ${ }^{3}$ The strategy thereby developed identifies five objectives to be reached in order to build a "smart, sustainable and inclusive" Europe, which are translated into eight quantitative indicators or targets (Table 1) and are achieved through seven flagship initiatives.

Table 1 Europe 2020: objectives for Europe 2020

\begin{tabular}{|c|c|c|}
\hline$N$. & Topic & Targets 2020 \\
\hline 1 & Employment & 1. $75 \%$ of the 20 - to 64 -year-old individuals to be employed \\
\hline 2 & Research and development (R-and-D) & 2. $3 \%$ of the EU's GDP to be invested in R-and-D \\
\hline 3 & $\begin{array}{l}\text { Climate change and energy } \\
\text { sustainability }\end{array}$ & $\begin{array}{l}\text { 3a. Greenhouse gas emissions } 20 \% \text { lower than in } 1990 \\
\text { 3b. } 20 \% \text { of energy from renewable } \\
\text { 3c. } 20 \% \text { increase in energy efficiency }\end{array}$ \\
\hline 4 & Education & $\begin{array}{l}\text { 4a. Reducing the rates of early school dropout to less than } 10 \% \\
4 \mathrm{~b} \text {. At least } 40 \% \text { of } 30 \text { - to } 34 \text {-year-old citizens to complete third-level } \\
\text { education }\end{array}$ \\
\hline 5 & Fighting poverty and social exclusion & 5. At least 20 million fewer people in or at risk of poverty and social exclusion \\
\hline
\end{tabular}

Note: GDP=gross domestic product.

In the area of education, EU2020 thereby sets two targets (Table 1). Gros and Roth (2008) highlight the fact that the second of these targets is particularly relevant for the role of education in increasing employability, strengthening competitiveness and enhancing long-term growth. EU2020, through its flagship initiatives, supports and boosts various examples of stakeholders' cooperation at the service of the socioeconomic growth of the EU, based on cooperation in the so-called Knowledge Triangle (KT). The KT is a policy paradigm that relies on the need for an integrated approach to research, innovation and education policy. Within this approach, knowledge creation is addressed as a systemic process, based on both the interaction and the interlinked relations among these three elements. EU2020 inherits the KT paradigm from the Lisbon Strategy and commits to reinforce its functioning through a set of complementary activities. ${ }^{4}$

In this sense, the framework provided to universities as part of EU2020 is not limited to the education and research policies, but it includes a wider range of possible contributions of HEIs to the economy and society. Such mechanisms are mainly activated through the Horizon 2020 Programme (H2020), which is the main financial instrument for implementing the EU2020 Strategy. ${ }^{5}$ Accordingly, the mechanisms thereby activated include various options for universities' engagement with and for society, ${ }^{6}$ resulting in a cross-cutting role for the HEIs in all the axes and Work Programmes of H2020 itself, precisely based on the learning interaction between research, science, education, societies and economies.

\footnotetext{
${ }^{3}$ The elaboration of EU2020 has been significantly influenced by the effect of the financial and economic crisis in the EU; thus, the programme explicitly intends to address the main global challenges that Europe is currently facing: from the demographic change to the increased international competition, up to the sustainability of the EU financial systems and the fight against climate changes.

${ }^{4}$ Among those, the European Institute of Innovation and Technology (EIT) is an independent EU body set up in 2008 to enhance Europe's ability to develop new products, services and ideas by creating favourable environments for innovation and bringing together different actors such as industries, small- and medium-sized enterprises, research centres and universities. Other additional initiatives are mainly accomplished through the Erasmus+ Programme, in particular for supporting university-businesses cooperation and boosting entrepreneurship. Support to research activities and researchers is mainly provided by the Marie Skłodowska-Curie Actions, through ad hoc calls for proposals launched within the framework of the Horizon 2020 (H2020) Programme.

${ }^{5} \mathrm{H} 2020$ is the financial instrument of the European Commission for implementing the Innovation Union initiatives of the EU2020 Strategy. H2020 is built around three priorities or pillars related to the following: (i) promoting excellence in science (the Excellent Science pillar); (ii) promoting the EU industrial leadership; (iii) addressing the global challenges identified by EU2020, which are translated into the Societal Challenges (SCs) related to seven different areas and sectors. These are listed as follows: SC1: health, demographic change and well-being; SC2: food security, sustainable agriculture, marine and maritime research, and the bio-economy; SC3: secure, clean and efficient energy; SC4: smart, green and integrated transport; SC5: climate action, resource efficiency and raw materials; SC6: inclusive, innovative and reflective societies; and SC7: secure societies.

${ }^{6}$ Such mechanisms include the elaboration, within H2020, of an ad hoc axis, identified by the Science With And For Society (SWAFS) Work Programme, aimed at building "effective cooperation between science and society, to recruit new talent for science and to pair scientific excellence with social awareness and responsibility" (EC, 2011).
} 


\section{University knowledge exchange and the SKIN Project \\ Djelveh, Contò}

In the next paragraph, we present the rationale and scope of the Short supply chain Knowledge and Innovation Network (SKIN) project as a theoretical example of multi-actor cooperation aimed at promoting knowledge exchange in a given sector. Because the project is funded under H2020, this will furthermore allow giving some practical examples on how the mechanisms provided at the institutional level from the European institutions can actually facilitate universities to work as "knowledge hubs" in modern societies (Yusuf, 2008).

The SKIN Project is a relevant example of the role of universities for knowledge exchange because the universities involved in the project are not the unique creators of knowledge, but knowledge is rather seen as an interactive and circular process involving all relevant actors and stakeholders in the field covered by the project scope. At the same time, the SKIN structure recognises the crucial role of HEIs in managing knowledge exchange because the project has been impulse, prepared and will be implemented under the coordination of one research organisation, specifically the University of Foggia. Last but not least, the project intends to address the main issues connected with the emergence of the idea of knowledge exchange, thus understanding and providing practical and successful examples of the social processes of knowledge exchange. To this extent, one of the main challenges of the project thereby is the capacity of the involved actors to cooperate and, thus, rests on the mechanisms activated by the project and monitored by the University of Foggia in order to ensure such collaboration.

\section{University and the social process of knowledge exchange: the SKIN Project}

SKIN, acronym for Short supply chain Knowledge and Innovation Network, is the European thematic network on Innovative Short Food Supply Chain Management, funded by H2020. ${ }^{7}$ The SKIN Project started in November 2016 and brings together 20 partners in 14 countries in the area of short food supply chains (SFSCs), coordinated by the University of Foggia. The project has the ambition of promoting an interactive innovative model aimed at improving knowledge exchange between academia and practitioners of the management of SFSCs and thus contributing to reconnecting EU food producers and consumers, or, more generally speaking, citizens.

The overall rationale of the SKIN Project is based on the desire of consortium members to systematise a panEuropean knowledge base and its community of practice on the theme of SFSCs. In this area, existing knowledge appears to be highly fragmented into smaller, often regional or local, communities and experiences. The SKIN Project is thereby a good example showing that the role of universities goes beyond the production of research results and includes the elaboration of methods for facilitating the circulation of already existing knowledge that is not available for the practitioners. This has the positive feature of not reinventing the wheel and, at the same time, engaging social sciences and scientists in order to ensure access to research outcomes and encourage lifelong learning.

The SKIN partnership is a consortium of practitioners, researchers and intermediary actors, built within a multi-actor logic, ${ }^{8}$ to advance innovation and efficiency of European SFSCs. The SKIN partnership involves organisations with complementary types of knowledge, such as farmers, innovation support and research organisations as well as technical partners, ${ }^{9}$ as shown in Table 2.

Table 2 The SKIN Project Consortium (organisations and countries)

\begin{tabular}{llll}
\hline Farmers' organisations & $\begin{array}{l}\text { Innovation support } \\
\text { organisations }\end{array}$ & Research organisations & Technical partners \\
\hline Confagricoltura (IT) & TEAGASC (IE) & UNIFG (IT) & CKA (BE) \\
Cooperativas Agroalimentarias de Espana (ES) & Innovatiespunt (BE) & UGent (BE) & EFB (UK) \\
ZLTO (NL) & SEGES (DK) & EQA (PL) & YOURIS (BE) \\
& ACTIA (FR) & CERSHAS (HU) & \\
& Campden BRI (HU) & \\
& AgrarVerein (AT) & \\
& C\&A Ltd (UK) & \\
& CLS (SK) & \\
& Biosense (RS) & \\
& Wirelesslnfo (CR) & \\
&
\end{tabular}

The SKIN Consortium will furthermore engage with external stakeholders and international experts (producers, customers, researchers, NGOs, SMEs, local administrations, as well as extension and innovation services), thus aiming to engage the whole range of stakeholders interested in the topic of SFSCs. ${ }^{10}$ By doing this, the SKIN Project implements a cooperative, participatory and bottom-up approach aimed at promoting an effective circulation of knowledge among the different actors and stakeholders involved. This is illustrated in Fig. 1, which shows how the

\footnotetext{
${ }^{7}$ The project has been funded under the Second Societal Challenge of Horizon 2020 - Food security, sustainable agriculture and forestry, marine and maritime and inland water research and the bioeconomy - by responding to a specific call for proposals closed in February 2016.

${ }^{8} \mathrm{~A}$ multi-actor approach aims at promoting demand-driven innovation through the involvement of key actors with complementary types of knowledge and who should cooperate together in order to achieve shared and common goals (EC, 2015).

${ }^{9}$ The role of the three technical partners is functional to the achievement of some specific activities (e.g. as for the construction of the project's website).

${ }^{10}$ For a comprehensive list of universities' stakeholders, please refer to Benneworth and Jongbloed (2009).
} 


\section{University knowledge exchange and the SKIN Project \\ Djelveh, Contò}

bottom-up approach will trigger an interactive circle of information and knowledge between academia and practitioners, thus simultaneously promoting demand-driven innovation and innovation-driven research. Due to such bottom-up approach, built on the real needs of the SFSC sector, the SKIN Project fosters a better alignment of research and innovation with the values, needs and expectations of society, consistent with the principles of Responsible Research and Innovation (EC, 2011).

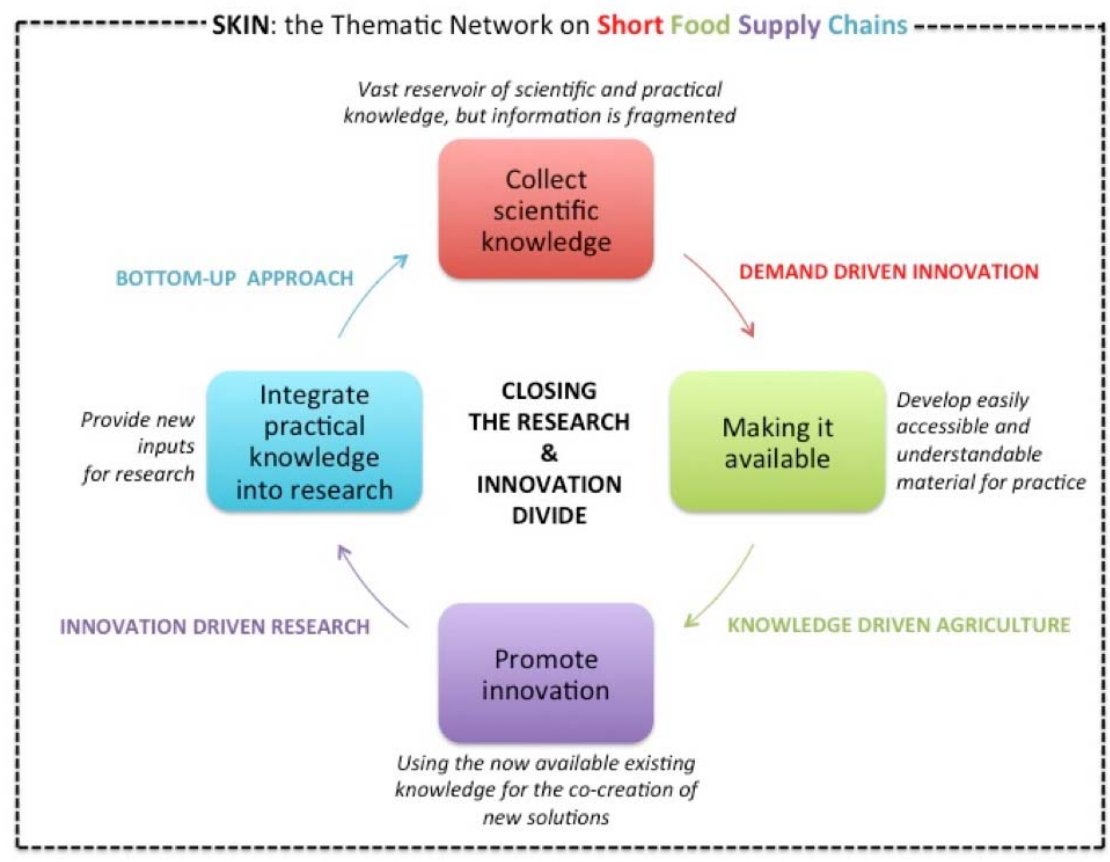

Fig. 1 SKIN approach to knowledge exchange.

The SKIN Project is a Coordination and Support Action ${ }^{11}$ (CSA), and as such, it does not perform research activities. Nevertheless, the project is coordinated by the University of Foggia and includes three other research organisations within the partnership. The role of HEIs in SKIN is thereby strongly focussed on activities that are not among the traditional missions of universities, but it rather ranges over the activities of management, coordination and support. Coordination is mainly related to the activities aimed at community building and knowledge sharing, whereas support activities deal with the deployment of training sessions to foster the achievement of innovative ideas and projects. Universities have, thereby, a crucial role in the deployment of the whole SKIN process which goes beyond research and education. This is also consistent with the lifelong and life-wide learning approach, because the main educational activities carried out by the project are related to practical coaching and training for SFSC practitioners.

Consistent with the definition provided by the European Commission, ${ }^{12}$ SKIN develops and applies a multi-actor approach in order to foster innovation based on the co-creation of contents between the different and complementary actors involved in the project. The SKIN multi-actor logic allows identification of the SKIN approach to knowledge exchange. This is based on four main elements:

- The presence within the consortium of partners with complementary types of knowledge;

- The methods used to ensure quality and quantity of knowledge exchanges along the project;

- The configuration of a structured organisation and management all along the project.

- The engagement strategy developed and implemented to involve actors from the broad community of SFSCs at different regional scales, as well as at the international level.

The multi-actor approach in SKIN is thereby reflected not only in the multidisciplinary structure and composition of the consortium but also in the structure and rationale of the proposed activities and, in particular, in the SKIN engagement strategy. This is aimed at involving and integrating stakeholders from the whole value chain beginning from the project planning preparation until its end. The SKIN engagement strategy will thereby identify actors, methods and opportunities to aggregate around SKIN a large and representative, multi-party community of stakeholders. The engagement strategy will furthermore ensure the quantity and quality of knowledge exchange achieved through SKIN and organised both virtually and physically.

The SKIN engagement strategy thereby precisely focusses on the social processes of knowledge exchange. Special attention will be therefore devoted to the identification of the workshops' learning methods and to their rationale for

\footnotetext{
${ }^{11}$ Within H2020, three types of initiatives are funded: (i) Research and Innovation Actions (RIAs); (ii) Innovation Actions (IAs) and (iii) Coordination and Support Actions (CSAs).

${ }^{12}$ See footnote number 7 .
} 


\section{University knowledge exchange and the SKIN Project \\ Djelveh, Contò}

deployment, which will follow a problem-solving approach. The Workshop animation methods will be defined in detail based on the principles of participatory action research and participative learning. Therefore, the workshops will use a collaborative learning approach that assumes that (i) learning is a non-linear, highly dynamic process; (ii) many outcomes of learning cannot be known in advance; and (iii) understanding must be built up through experience. This will allow focussing on the importance of participants' experiences and identities, as well as encourage people to share information, learn from each other and work together to solve common problems, because all participants will be equitably involved in the process. To this extent, the project will use different learning methods from facilitation techniques, thus enabling face-to-face interaction and participation in multiple-stakeholder workshop settings (Hogan and Broome, 2013), to social learning analytics, thus focussing on such elements of learning that are considered as relevant in a participatory online culture (Buckingham and Ferguson, 2012). Facilitation techniques will be based on the most recent developments, including evolving theories and practices of learning, thus including world café, storytelling, best practice exchange, peer reviews, creative laboratories, triangular interviews, positive elicitation, repertoires of innovation support, as well as multimedia and blended online and face-to-face learning processes and other methods of knowledge brokering during multiple-stakeholder meetings (Karner et al., 2011). In particular, they will draw on collaborative and collective learning, focussing on the use of social learning processes for achieving systemic innovation for sustainable development (Colvin et al., 2014), as well as on multimedia and social media tools for ensuring that exchange is based on interactions, rather than linear transfer of knowledge, among different stakeholders. To this extent, social multimedia tools will be used to feed the SKIN community and encourage its members to actively contribute to discussions in order to assess whether learning is effective, as well as to adjust the means when needed, due to the interaction among the participants. The principle behind interaction is participatory action research, in which researchers are embedded in a complex system of interlinked cultural, social and economic relationships, which influences the whole research process, from their choices, activities, approaches, paradigms, methodologies, up to the results themselves (Adelman, 1993). Based on such an approach, the objective is not just to collect data on a given reality, but it is rather to currently influence and thus transform such reality, thus looking at the dynamic relations between actors and contexts to come up with concrete solutions to concrete problems. In the SKIN Project, the dialogue among the different stakeholders, the further analysis of practitioners' needs and of the state-of-the-art for SFSCs in the EU, allowed identification of nine categories of problems or bottlenecks that will be addressed by the project's activities and are related to the following: (i) business development support; (ii) distribution and chain integration; (iii) logistics; (iv) production; (v) regulation; (vi) skills; (vii) consumption; (viii) funding; (ix) new technologies. To this extent, participatory action research in SKIN will apply methods and techniques derived from traditional research, interpretative research and experiential research, with the aim of finding concrete solutions in a given and dynamic context (Trinchero, 2009). This results in a seven-step process, structured as follows:

1. Identifying a problem or bottleneck: each workshop will focus on one or two of the identified bottlenecks.

2. Developing the multidisciplinary research group: based on the SKIN multi-actor approach.

3. Planning an intervention for the identified problem, engaging in an intense dialogue with the SKIN stakeholders: through international workshops, collaborative foresight exercises, local roundtable (the SKIN regional nodes) and social/interactive media.

4. Acting for achieving such intervention: through specific coaching activities, both face-to-face and virtual.

5. Measuring the effect of such intervention: based on the number of innovative projects and initiatives initiated through the SKIN engagement activities.

6. Evaluating the qualitative and quantitative effects of the implemented solution: based on the Quality Assurance Plan developed at the beginning of the project.

7. Monitoring the process: which is related to the general project's management and coordination.

Based on the outcomes of such workshops, specific coaching activities will be carried out with the aim of coordinating the delivery of support and guidance to emerging innovation groups identified through the SKIN engagement strategy. The rationale of this activity is to help stakeholders set up innovation projects based on the uptake of research results and on academia-business collaboration. Such activities will thereby be oriented to empower the participants for addressing concrete innovation challenges and with the final aim of fostering the fulfilment of innovation within the sector.

\section{Conclusions}

Based on the literature on knowledge exchange and the KT, the SKIN Project represents an example for implementing a systemic approach to university-business-society dialogue. While putting in practice the approach theorised by the policymakers and using the mechanisms made available from public financing, the SKIN Project allows having a wider look at the numerous, interlinked and different possible activities carried out by universities that are able to generate social and economic impacts. This opens a wider range of possible contributions of social science (in particular, in the economics, sociology and pedagogical fields) to the general objectives of growth and development identified at a policy level. This also implies an important change for researchers, from being a simple "source" of 


\section{University knowledge exchange and the SKIN Project Djelveh, Contò}

knowledge to getting engaged in knowledge exchange processes. To this extent, what seems to matter is the ability of HEIs to activate processes of knowledge exchange, which depend on and are consistent with the socioeconomic context in which each university is embedded. As a valid example of such an approach, all the four HEIs involved in the SKIN Project are embedded in socioeconomic contexts where the agro-food sector represents an important share of the local/regional economic activities. This should demonstrate that practices of knowledge exchange differ and depend on the type and profile of universities, which are strongly linked to the socioeconomic framework in which they operate. One of the key issues is therefore the understanding of such context, how it evolves and how it applies to these institutions (Benneworth, 2011). Hence again, the role of humanities and social sciences, as well as the ability of scientists and researchers coming from different fields to cooperate for multidisciplinary goals, is crucial for the success of the process of knowledge circulation with and for society. In addition, the results of previous research carried out at the EU level (for instance, the outcomes of the FOODLINKS ${ }^{13}$ and SOLINSA ${ }^{14}$ projects) within the framework of knowledge exchange highlight the relevance of "creative management", conceived as the management of a group process, as opposed to the management of simple tasks (Moschitz, 2013), in the process of knowledge exchange.

To summarise, the SKIN Project proposes several means for universities to exchange knowledge with outside partners, consistent with the knowledge exchange approach (Table 3).

Table 3 Ways in which universities may exchange knowledge with outside partners (adapted from Benneworth, 2011)

\begin{tabular}{|c|c|c|}
\hline Source of knowledge exchange & Ways to deliver knowledge exchange & $\begin{array}{l}\text { SKIN ways to deliver } \\
\text { knowledge exchange }\end{array}$ \\
\hline 1. University means of giving knowledge & Mechanism for delivering service & Engagement strategy \\
\hline \multirow{2}{*}{$\begin{array}{l}\text { 2. Equipment that outside party uses in own } \\
\text { learning/research activities }\end{array}$} & 2a. Use of equipment, premises and laboratories & \multirow[b]{2}{*}{ Strategic management } \\
\hline & $\begin{array}{l}\text { 2b. Use of teachers and students to make direct } \\
\text { contribution }\end{array}$ & \\
\hline \multirow[t]{2}{*}{ 3. Sale of "transmission of knowledge" as service } & 3a. Delivering training & Coaching activities \\
\hline & $\begin{array}{l}\text { 3b. A sort of private contract between the } \\
\text { stakeholder and the university }\end{array}$ & Promotion of RRI \\
\hline 4. Provision of report, advice and guidance to user & $\begin{array}{l}\text { The university comes into the stakeholder as an } \\
\text { outside expert }\end{array}$ & $\begin{array}{l}\text { Coordination and strategic } \\
\text { management }\end{array}$ \\
\hline $\begin{array}{l}\text { 5. Helping external party to solve a particular } \\
\text { problem }\end{array}$ & $\begin{array}{l}\text { University engages a stakeholder request in } \\
\text { developing solutions }\end{array}$ & Bottom-up approach \\
\hline $\begin{array}{l}\text { 6. Solving a particular problem on behalf of the } \\
\text { actor }\end{array}$ & $\begin{array}{l}\text { University delivers a service that is compatible } \\
\text { with its institutional status }\end{array}$ & Multi-actor approach \\
\hline
\end{tabular}

Note: $\mathrm{RRI}=$ responsible research and innovation.

To this extent, empirical results already available (Moschitz, 2013; Herzon et al., 2014) demonstrate that the creative management of interactive processes has positive impacts in the process of knowledge exchange, also suggesting some critical steps for addressing the new role of researchers in knowledge exchange processes through the creative management of interactive processes, such as the importance of (i) cleared and shared objectives, (ii) mutual trust, (iii) planning time, (iv) leadership and facilitation, (v) empowerment and (vi) co-creation.

What matters therefore are the quantity and the quality of interactions and exchange between researchers and other stakeholders, in particular, the methodologies and tools activated in order to ensure such processes, as well as the whole management (creative management) and coordination of the action-research programme, as summarised below:

- Coordination: community building for preparing a proposal based on a bottom-up approach.

- Strategic management: use of equipment, premises, laboratories and universities' staff (both researchers and administrative) for ensuring an effective and creative management of the project's activities.

- Collection and rationalisation of knowledge that is already existing but not structured and not always available for practitioners in order to promote demand-driven innovation.

- Promotion of responsible research and innovation (RRI) considering the fostering of innovation-driven research and thus generating new knowledge based on the outcomes of innovative processes, services and products' diffusion.

- Methods and tools for organising effective knowledge exchange with and for societies and for encouraging a trans-disciplinary and inter-sectorial dialogue among different stakeholders and organisations. To this extent, a pivotal role will be covered by the SKIN dissemination strategy and, in particular, by the social media strategy. Social media have become a very popular means of disseminating information across heterogeneous target groups, entering into the scientific sphere (for instance, Beninger et al., 2014) and at the same time evolving as prominent communication channels. Social media tools will be particularly used for organising, promoting and monitoring interactions among the SKIN community with the aim of engaging with professional audience,

\footnotetext{
${ }^{13}$ For more information, please refer www.foodlinkscommunity.net.

${ }^{14}$ For more information, please visit: www.solinsa.net.
} 


\section{University knowledge exchange and the SKIN Project \\ Djelveh, Contò}

stakeholders and citizens, consistent with the identified target groups of the project. These have been grouped in three different categories (primary agro-food actors; knowledge actors; and institutional actors), and ad hoc quantitative targets have been set up by the SKIN Consortium.

\section{References}

Abreu, M., Grinevich, V., Hughes, A., Kitson, M., Ternouth, P. (2008). Universities, Businesses and Knowledge Exchange. Report for Council for Industry and Higher Education, and Centre for Business Research

Adelman C. (1993). Kurt Lewin and the Origins of Action Research, Educational Action Research, 1:1, 7-24, DOI: 10.1080/0965079930010102. Retrieved from: http://dx.doi.org/10.1080/0965079930010102

Beninger K., Fry A., Jago N., Lepps H., Nass L. \& Silvester H. (2014). Research using Social Media; Users' Views. NatCen Social Research: London.

Benneworth, P. \& Jongbloed, B.W.A (2009) Who matters to universities? A stakeholder perspective on humanities, arts and social sciences valorization, Higher Education DOI 10.1007/s10734-009-9265-2.

Benneworth P. (2011). Towards A Strategic Management Agenda For University Knowledge Exchange. Retrieved from: http://www.eurashe.eu/

Buckingham Shum, S. \& Ferguson, R. (2012). Social Learning Analytics. Journal of Educational Technology \& Society, 15 (3), 3-26.

Cantner, U., Meder, A. \& Wolf, T. (2011). Success and failure of firm's innovation co-operations: The role of intermediaries and reciprocities. Regional Science, 90, 2, 313-329.

Colvin J., Blackmore C., Chimbuya S., Collins K., Dent M., Goss J., Ison R., Roggero P. \& Seddaiu G. (2014). In search of systemic innovation for sustainable development: A design praxis emerging from a decade of social learning inquiry. Research Policy 43 (2014) 760-771

Contò, F., Faccilongo, N., La Sala, P., Dicecca, R. 2013. Cloud approach for short chain administration. PROCEDIA TECHNOLOGY. Vol. 8 pp. 600-605. Elsevier, Oxford, UK. ISSN: 2212-0173, DOI:10.1016/j.protcy.2013.11.085

Cruickshank, L., Whitham, R., Morris, L. (2012) Innovation through the design of knowledge exchange and the design of knowledge exchange design. 2012 International Design Management Research Conference 453-460

Edquist, C. (2006), "Systems of innovation perspectives and challenges", In Fagerberg, J., Mowery, D.C. \& Nelson, R.R. eds. The oxford handbook of innovation. New-York: Oxford University Press Inc.

European Commission, EC (2008). Needs and Constraints Analysis of the Three Dimensions of Third Mission Activities. Retrieved from: http://e3mproject.eu/

European Commission, EC (2010) Europe 2020: A European strategy for smart, sustainable and inclusive growth, Brussels: CEC, COM (2010) 2020. Retrieved from: http://ec.europa.eu/eu2020/pdf

European Commission, EC (2011), Communication From The Commission To The European Parliament, The Council, The European Economic And Social Committee And The Committee Of The Regions. Horizon 2020 - The Framework Programme for Research and Innovation. COM(2011) 808 final.

European Commission, EC (2015). Calls for proposals and related activities under the 2016-17 work programmes under Horizon 2020 - the Framework Programme for Research and Innovation (2014-20) and under the Research and Training Programme of the European Atomic Energy Community (2014-18) complementing Horizon 2020. Official Journal of the European Union (2015/C 399/02)

Gros, D. and F. Roth (2008), The post-2010 Lisbon Process: The key role of education in employment and competitiveness, CEPS Working Document No. 308, Centre for European Policy Studies, Brussels.

Herzon, I, Macken-Walsh, A., McCann, K., Pietx, J. (2015) Empowering Farmers operating on High Nature Value Farmland: a solutions-oriented discussion paper, European Innovation Partnership (EIP) Focus Group on High Nature Value (HNV) Farming, September 2015

Hogan, M.J. \& Broome, B. (2013). Wellbeing in Ireland - Designing Measures and Implementing Policies, Collective Intelligence Conference Report, NUI, Galway.

Jacobs N. (2013). Measuring Knowledge Exchange. Paper presented at The Knowledge Exchange, An Interactive Conference, 26th and 27th September 2013, Lancaster University.

Jongbloed, B., Enders, J. \& Salerno, C. (2008). Higher education and its communities: interconnections, interdependencies and a research agenda, Higher Education, 56, 303-324

Karner S., Rohracher H., Bock B., Hoekstra F. \& Moschitz H. (2011) Knowledge brokerage in communites of practice: synthesis report on literature review. Retrieved from: http://www.foodlinkscommunity.net/ 


\section{University knowledge exchange and the SKIN Project \\ Djelveh, Contò}

Kitson M., Howells J., Braham J., \& Westlake S. (2009). The Connected University Driving Recovery and Growth in the UK Economy. Retrieved from: www.nesta.org.uk

Kline, S. J. \& Rosenberg, N. (1986) An overview of innovation, in R. Landau and N. Rosenberg, The positive sum strategy, Washington DC: National Academy Press.

Lasagni, A. (2012), "How can external relationships enhance innovation in SMEs? New evidence for Europe", Journal of Small Business Management, 50, 2, 310-339.

Lockett, N., Kerr, R., Robinson, S. (2008) Multiple Perspectives on the Challenges for Knowledge Transfer between Higher Education Institutions and Industry. International Small Business Journal, 26:6 661-681

Maniscalco, R.S. (2010). The Impact of the European Policies on the New Skills for the New Jobs. Review of European Studies. 2(2): 54-66.

Mitton, C., Adair, C. E., McKenzie, E., Patten, S. B., \& Perry, B. W. (2007). Knowledge transfer and exchange: review and synthesis of the literature. Milbank Quarterly, 85(4), 729-768.

Moschitz H. (2013). From Project Management to Process Management: Effectively Organising Transdisciplinary Projects. GAIA 22/3 (2013): 211-213. ISSN 0940-5550.

Paavola, S., Lipponen. L. \& Hakkarainen, K. (2004) Models of Innovative Knowledge Communities and Three Metaphors of Learning, Review of Education Research 74 (4), pp. 557-576.

Pittaway, L., Robertson, M., Munir, K., Denyer, D. \& Neely, A. (2004). Networking and innovation: A systematic review of the evidence. International Journal of Management Reviews, 5, 3-4, 137-168.

Tödtling, F. \& Trippl, M. (2005), "One size fits all? Towards a differentiated regional innovation policy approach", Research Policy, 34, 1203-1219.

Trinchero R. (2009). I metodi della ricerca educativa. Bari: Laterza.

Vorley, T. \& Nelles, J. (2008). (Re)Conceptualising the Academy: Institutional Development of and beyond the Third Mission, Higher Education Management and Policy, 20 (3), 119-135.

Yusuf, S. (2008) Intermediating knowledge exchange between universities and businesses. Research Policy $371167-$ 1174. 